\title{
Determination of rebar effect on dynamic characteristics and dynamic behavior of reinforced concrete bridges
}

\author{
Umut Ufuk Doğan ${ }^{1}$ iD, Ahmet Can Altunışık ${ }^{2}$ iD, Mustafa Ergün*3 (iD \\ ${ }^{1}$ Sivas Cumhuriyet University, Department of SMYO Building Inspection Program, Sivas, Turkey \\ ${ }^{2}$ Karadeniz Technical University, Department of Civil Engineering, Trabzon, Turkey \\ ${ }^{3}$ Bayburt University, Department of Civil Engineering, Bayburt, Turkey
}

\begin{abstract}
In this study, it is aimed to be searched the effect of the rebar on the structural behavior of reinforced concrete bridges formed with the finite element method. For this purpose, the numerical model of the bridge with known dimensions, material properties and rebar configuration was modeled using ANSYS finite element analysis program. In the first model, it was thought that the bridge was constructed using only concrete, rebar was not taken into consideration. Then the same bridge was modelled without changing the boundary conditions as if it was built by reinforced concrete material in which rebar and concrete were together and the modal analyses were carried out on this model again. The dynamic characteristics of the two different bridge models were determined using numerical methods and the effect of the rebar on these characteristics was presented by comparing them with each other. When the results obtained were examined, it was found that the rebar had no significant effect on the modal behavior of the bridge. Thus, not taking into account the rebar will provide a great convenience during the modeling stage. In addition, linear and nonlinear dynamic analyzes were performed on the reinforced and unreinforced finite element models of the bridge using the effective earthquake acceleration record of the Erzincan earthquake of 1992 and structural behavior was evaluated. The results are presented in comparison with the graphs and tables in this paper.
\end{abstract}

\section{Keywords}

ANSYS; Finite element bridge model; Modal analysis; Dynamic characteristic; Rebar effect; Linear time history analysis; Non-linear time history analysis.

Received: 23 December 2019; Accepted: 19 February 2020

ISSN: 2630-5763 (online) (C) 2020 Golden Light Publishing All rights reserved.

\section{Introduction}

All living and inanimate beings in the universe are in a state of invisible vibration. The characteristics of the structures that express these vibration states are expressed as the dynamic characteristics of the structure. Dynamic characteristics can be obtained using analytical, numerical and experimental methods. In this study, numerical models of smallscale bridges were created by using previously known properties (dimensions, material properties, boundary conditions, etc.) and modal analyzes were performed on these models using finite element method.

In the literature, there are many studies aimed at obtaining the dynamic characteristics of bridges by numerical methods [1-15].

When the studies done in previous years are examined, it is seen that the effect of rebar in

* Corresponding author

Email: mustafaergun@bayburt.edu.tr 
modeling stage is generally not taken into consideration in determining the dynamic characteristics of reinforced concrete bridges by numerical methods. Consideration of the rebar during the modeling phase causes a great waste of time and also causes great difficulties in the analysis phase. Therefore it is often neglected. But there is a lot of uncertainty as to what effect rebar has on the dynamic behavior of the structure. In order to eliminate these uncertainties, it was decided to carry out such a study.

In order to eliminate the uncertainties mentioned above, numerical studies were performed on a small scale reinforced concrete bridge. Firstly, in order to see the effect of rebar on dynamic characteristics, the bridge was modeled as reinforced and non-reinforced and free vibration analyses were performed on these models. Then, linear and nonlinear dynamic analyzes were performed on the reinforced and unreinforced finite element models of the bridge using the effective earthquake acceleration record of the Erzincan earthquake of 1992 and structural behaviors were evaluated.

\section{Material and method}

In this study, two different types of analyzes were carried out on the reinforced and unreinforced bridge models in accordance with the aim of the study. The first of these analyzes was the free vibration analysis, also known as modal analysis in the literature, used to determine the dynamic characteristics of bridges. The second one was the dynamic analysis of the time-domain using the actual earthquake records to predict the dynamic behavior of the structure at the time of the earthquake. These analyzes were performed for both linear and nonlinear behavior of the material. All analyzes were performed using ANSYS finite element program.

\subsection{Geometric features of model bridge}

The geometric properties of the bridge model considered in this study are given below. The bridge, which is $600 \mathrm{~cm}$ long, consists of a $300 \mathrm{~cm}$ mid space and two side cantilevers, each $150 \mathrm{~cm}$ long. The piers of the model bridge have $20 \times 40$ $\mathrm{cm} 2$ cross section and $110 \mathrm{~cm}$ height. Two and three dimensional views of the model bridge are given on Fig. 1 and 2. Dimensions are in terms of $\mathrm{cm}$.

The cross section of the bridge deck is $30 \mathrm{~cm}$ high and $40 \mathrm{~cm}$ base width with a single-cell box section, $60 \mathrm{~cm}$ wide and $600 \mathrm{~cm}$ long. Fig. 3 is a cross-sectional view of the model bridge.

\subsection{Material features of model bridge}

C30/37 class for concrete and S420 class for rebar with different diameters were used in all elements of the model bridge. Mechanical properties of these materials are given in Table 1.

\subsection{Numerical modeling with ANSYS}

Numerical modeling and analysis of the geometric and material properties of the model bridge given in the previous section were performed with ANSYS finite element package program. The properties of the finite element model of the bridge are given in the following sections respectively.

- The concrete parts of the bridge were modeled using SOLID65 type elements (Fig. 4) which have three different freedom of displacement in each $\mathrm{x}, \mathrm{y}, \mathrm{z}$ direction at each joint and which could be seen in concrete such as tensile, cracking, crushing, plastic deformation and creep.

- When the concrete parts of the model bridge, which was represented by the SOLID65 element, was divided into a square finite element at $2.5 \mathrm{~cm}$ (mesh) intervals, 35.224 elements and 51.366 nodes had occurred. (Fig. 5)

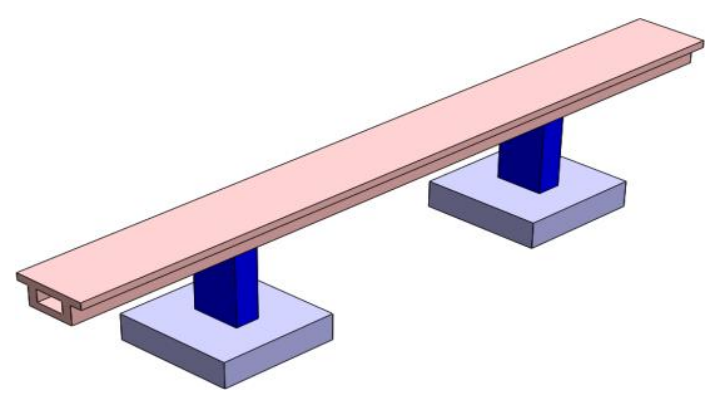

Fig. 1. Three-dimensional view of the model bridge 

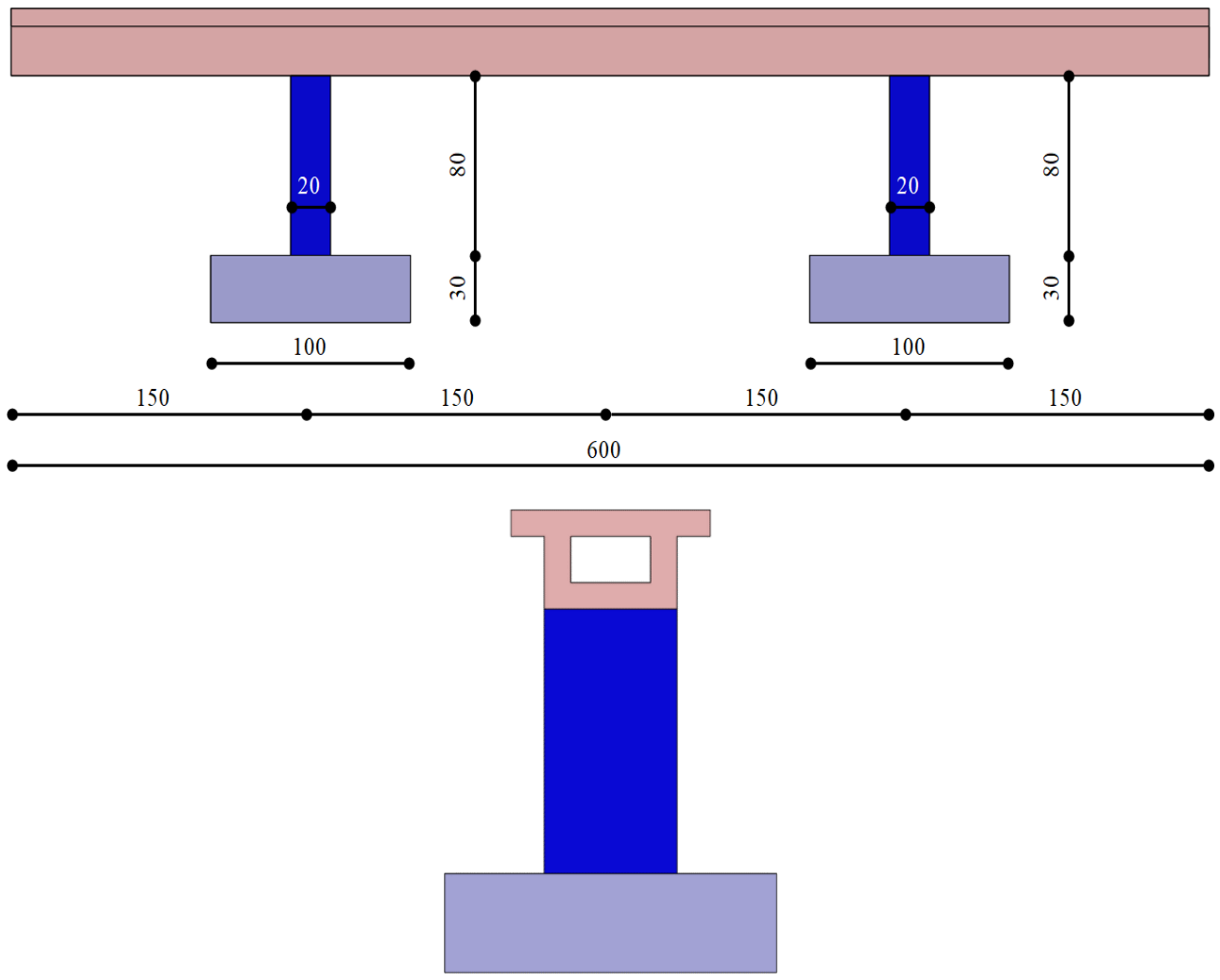

Fig. 2. Two-dimensional views of the model bridge
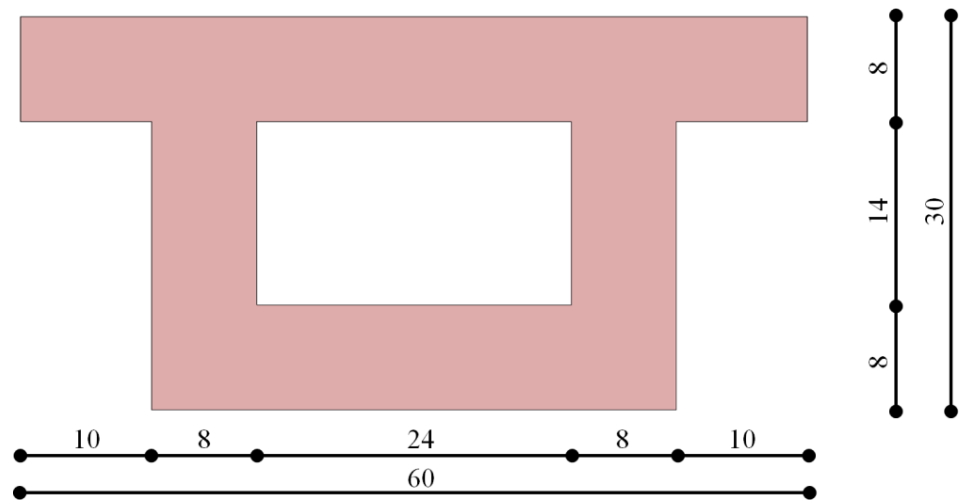

Fig. 3. Cross-section view of the model bridge

Table 1. Mechanical properties of concrete and rebar used in finite element analysis of model bridge

\begin{tabular}{cccc}
\hline \multirow{2}{*}{ Material } & $\begin{array}{c}\text { Modulus of Elasticity } \\
{\left[\mathrm{N} / \mathrm{m}^{2}\right]}\end{array}$ & $\begin{array}{c}\text { Poisson's Ratio } \\
{[-]}\end{array}$ & $\begin{array}{c}\text { Density } \\
{\left[\mathrm{kg} / \mathrm{m}^{3}\right]}\end{array}$ \\
\hline $\mathrm{S} 420$ & $2.06 \mathrm{E} 11$ & 0.3 & 7850 \\
$\mathrm{C} 30 / 37$ & $2.95 \mathrm{E} 10$ & 0.2 & 2500 \\
\hline
\end{tabular}




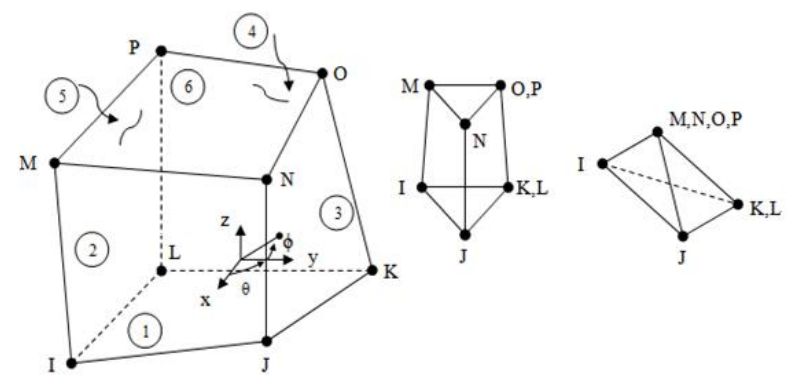

Fig. 4. SOLID65 element type
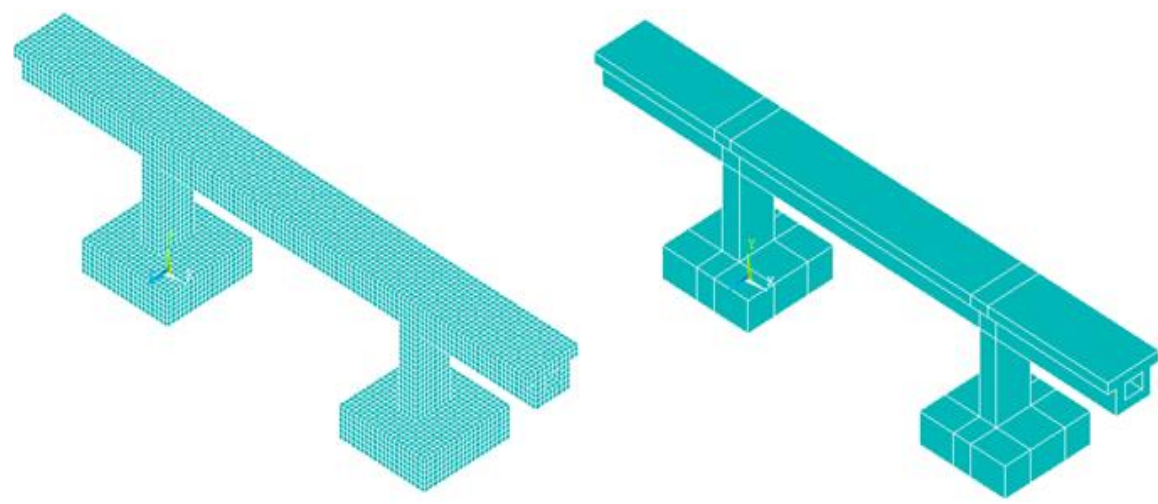

Fig. 5. Three-dimensional solid and finite element model of concrete bridge

- The rebar of the bridge were modeled using LINK180 type elements which have three different displacement freedoms in each $\mathrm{x}, \mathrm{y}, \mathrm{z}$ direction.(Fig. 6)

- The rebar of the model bridge represented by the LINK180 element were divided into square finite elements at $2.5 \mathrm{~cm}$ (mesh) intervals, resulting in 35.224 elements and 51.366 nodes.

(Fig. 7)

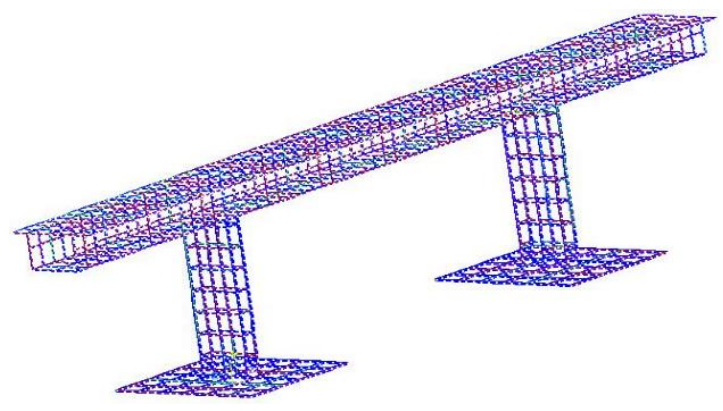

\subsection{Parameters of dynamic analysis in time domain}

For dynamic analysis of model bridges in time domain, acceleration record of Erzincan earthquake was used (Fig. 8). This acceleration record was taken into account in the analyzes for a time interval between $0-7$ seconds.

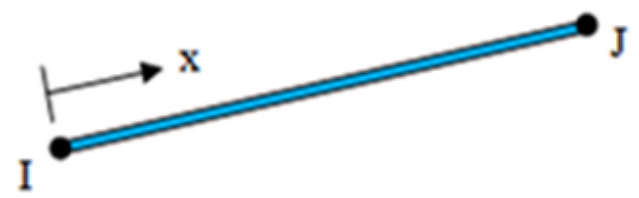

Fig. 6. LINK180 element type

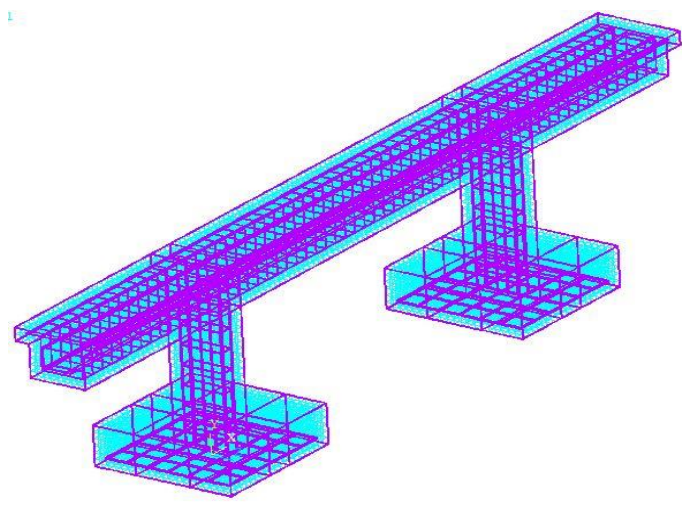

Fig. 7. Three-dimensional finite element model of rebar at the piers and deck of the model bridge 


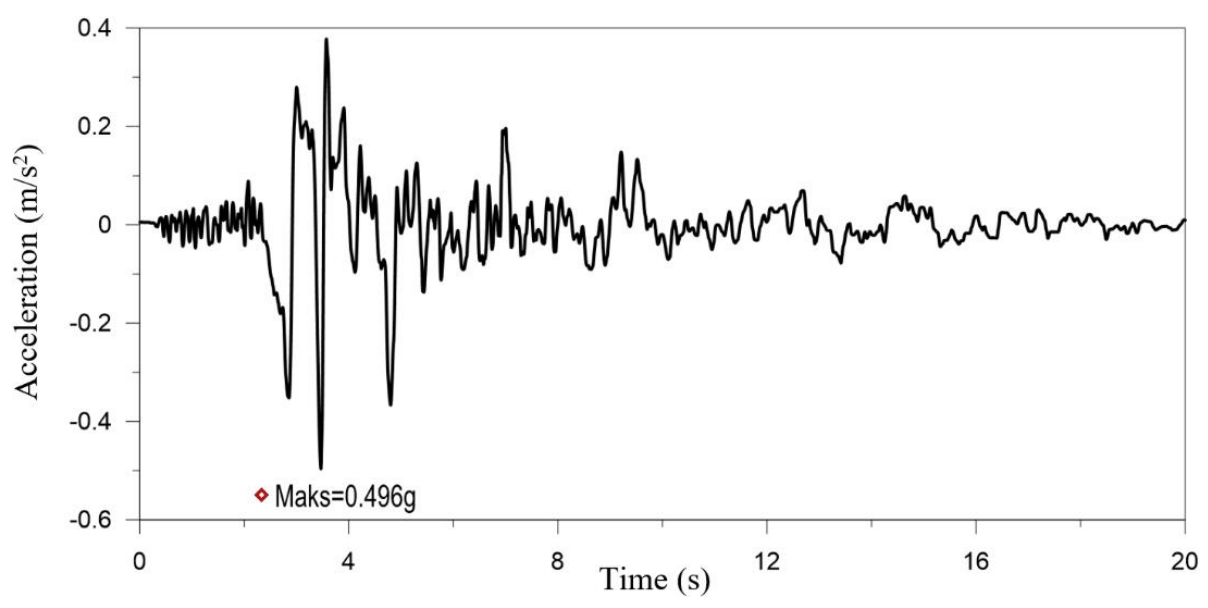

Fig. 8. Erzincan 1992 earthquake acceleration-time recording

In order to take account of changes in material properties during nonlinear dynamic analyzes, the ready-made material models presented by the program were not used, but instead stress-strain curve was defined with manual data entry to better reflect actual material behavior. Stress-strain values obtained according to Hognestat wrapped concrete model for concrete material were introduced as individual input data to the program and it was aimed to show the actual behavior of the material. Stress-strain values obtained for concrete material according to Hognestat model are shown in Table 2. The stress-strain graph generated by the program is given in Fig. 9.

Characteristic material values for $\mathrm{C} 30 / 37$ concrete were taken from TS500 and introduced as input data to the program. The stress-strain graph of the concrete generated by the program is given in Fig. 9. Characteristic material values for reinforcing steel S420 were taken from TS-708 and introduced as input data to the program. In addition, according to the material properties entered for S420 reinforcing steel, the stress-strain graph generated by the program is given in Fig. 9.

\section{Results}

\subsection{Dynamic characteristics of model bridges}

The first eight mode shapes of the reinforced and non-reinforced models of the bridge and the frequency values depending on these are shown in
Fig. 10 and the comparison of the frequency values of both models can be seen in Table 3 .

When Table 3 is examined, it is seen that the difference between the frequency values is around $2 \%$. This shows that the rebar modifies the dynamic characteristics very little and therefore does not have much effect on the modal behavior of the bridge.

\subsection{Dynamic behaviors of model bridges}

The dynamic behaviors of model bridges were determined by the results of linear and non-linear analysis in time domain. In the ANSYS finite element analysis program, the model bridge was first considered as a volume consisting of only concrete material without rebar, then as a model consisting of reinforced concrete material where concrete and rebar were together. In the linear and nonlinear analyzes performed on both models, 7 seconds of the effective ground acceleration records of the Erzincan earthquake were influenced by $0.005 \mathrm{sec}$ time intervals. Comparisons were made on the maximum displacement, maximum and minimum principal stress and maximum and minimum principal strain values at $\mathrm{t}=1.9 \mathrm{~s}$, which is the maximum acceleration value of the part of the earthquake acceleration record taken into account.

The results obtained from linear analyzes on non-reinforced concrete and reinforced concrete bridge models are given in Tables 4-8. 
Table 2. Stress-strain values for concrete material according to Hognestat Model

\begin{tabular}{ccl}
\hline Point & $\begin{array}{c}\text { Stress } \\
{\left[\mathrm{N} / \mathrm{m}^{2}\right]}\end{array}$ & Strain \\
\hline 1 & 8850000 & 0.0003 \\
2 & 15652000 & 0.0006 \\
3 & 22826000 & 0.0010 \\
4 & 27391000 & 0.0014 \\
5 & 28696000 & 0.0016 \\
6 & 29348000 & 0.0018 \\
7 & 30000000 & 0.0020 \\
\hline
\end{tabular}
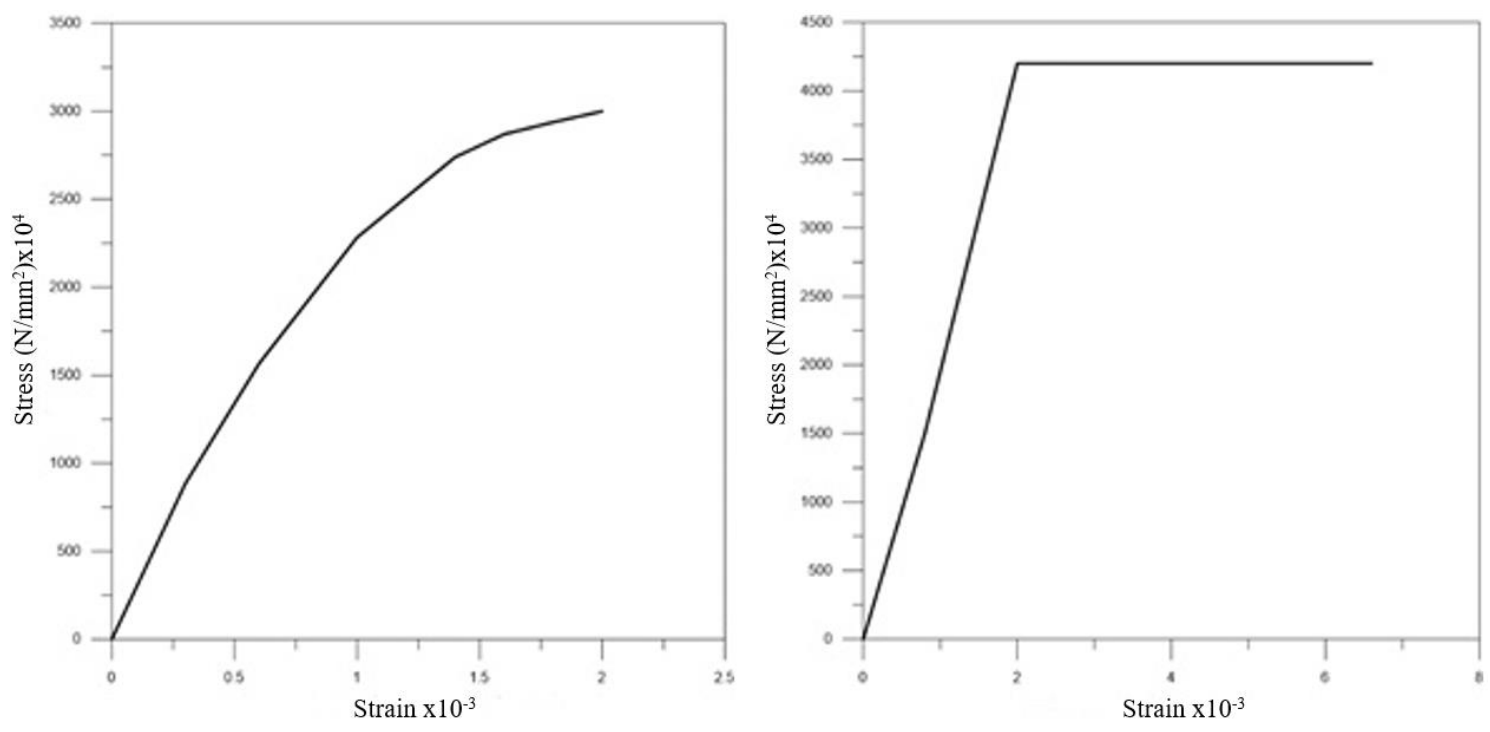

Fig. 9. Stress-strain graphs obtained according to the material properties entered for concrete and steel respectively
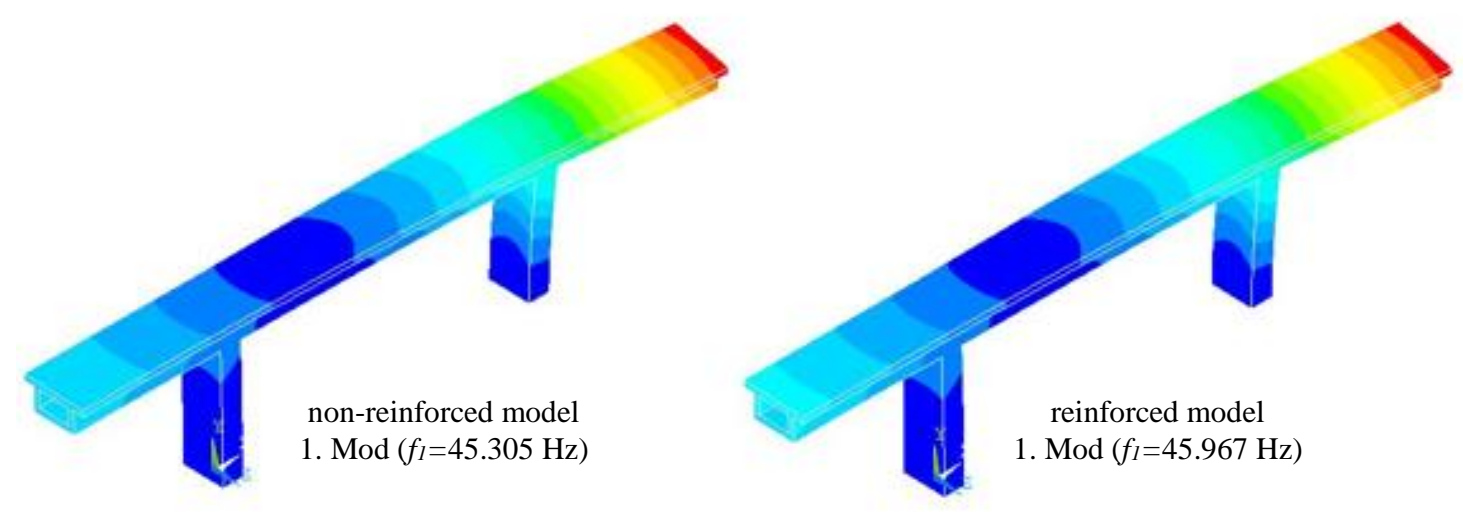

Fig. 10. The first eight mode shapes and frequencies of the model bridges 

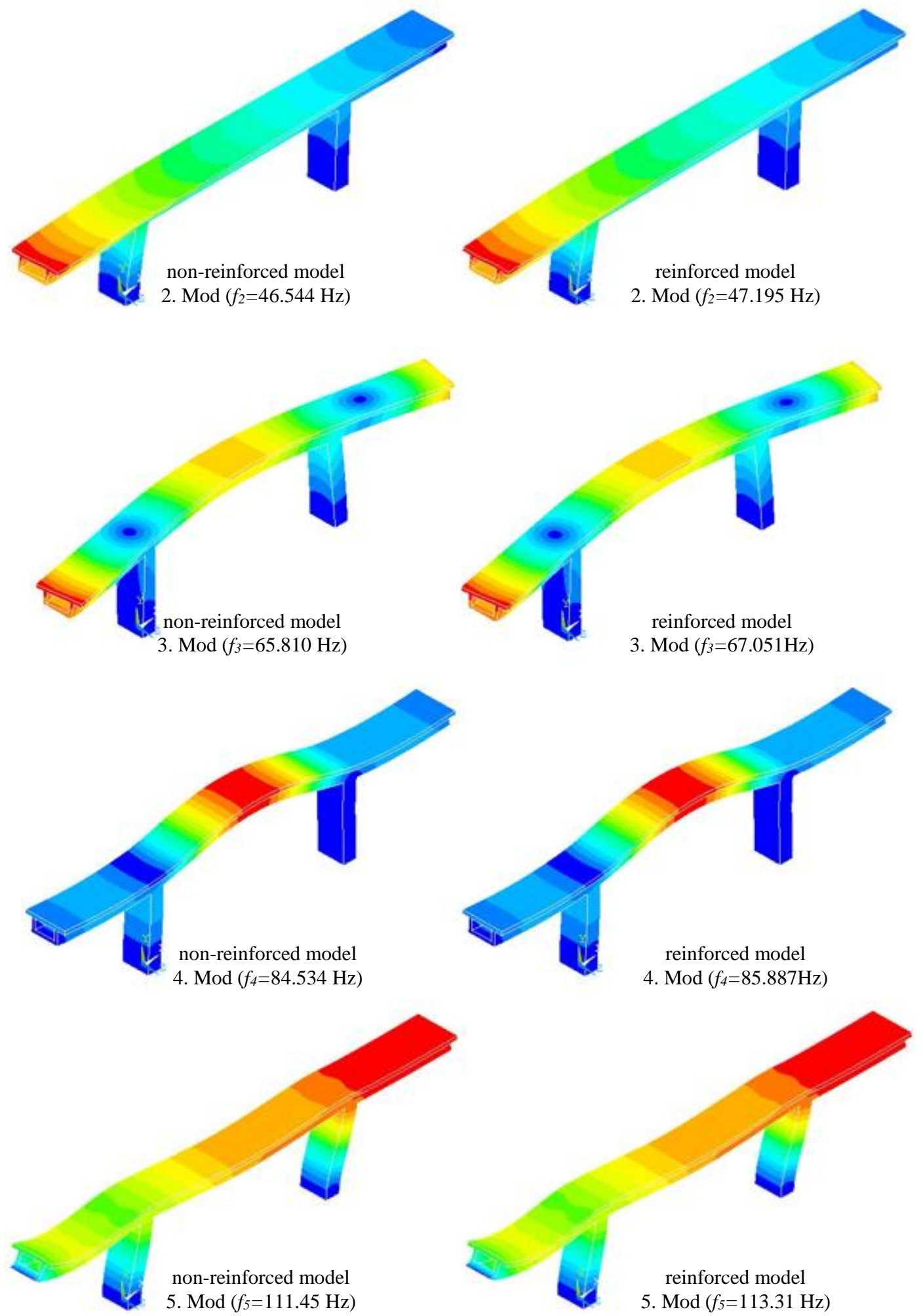

Fig. 10. Cont'd 

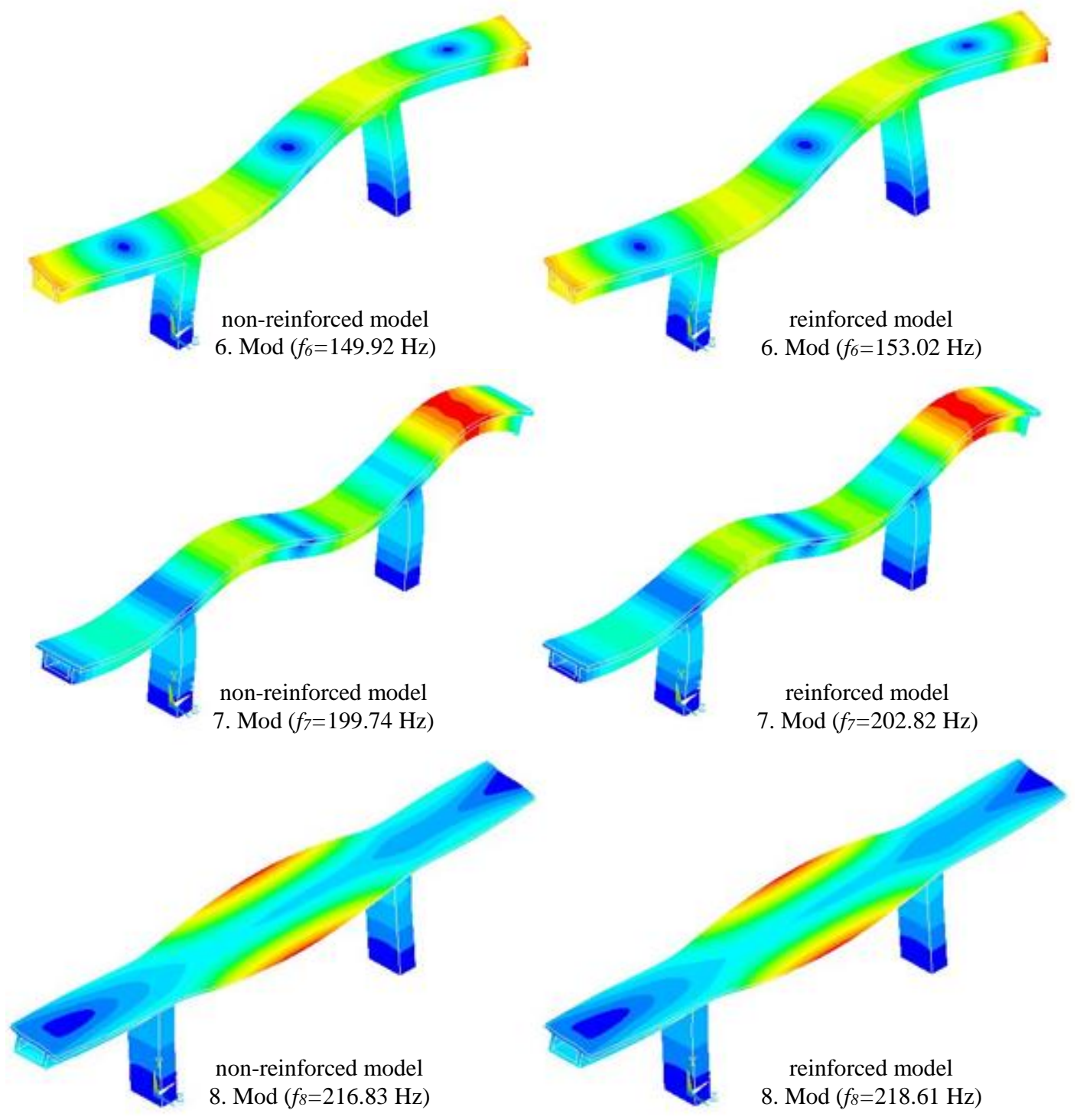

Fig. 10. Cont'd

Table 3. Comparison of frequency values of reinforced and non-reinforced bridge models

\begin{tabular}{cccc}
\hline Mod & $\begin{array}{c}\text { Concrete Model } \\
\text { Frequency }[\mathrm{Hz}]\end{array}$ & $\begin{array}{c}\text { Reinforced Concrete Model } \\
\text { Frequency }[\mathrm{Hz}]\end{array}$ & $\begin{array}{c}\text { Comparison } \\
\%\end{array}$ \\
\hline 1 & 45.305 & 45.967 & 1.46 \\
2 & 46.544 & 47.195 & 1.40 \\
3 & 65.810 & 67.051 & 1.89 \\
4 & 84.534 & 85.887 & 1.60 \\
5 & 111.45 & 113.31 & 1.67 \\
6 & 149.92 & 153.02 & 2.07 \\
7 & 199.74 & 202.82 & 1.54 \\
8 & 216.83 & 218.61 & 0.82 \\
\hline
\end{tabular}


Table 4. Maximum displacement results

\begin{tabular}{cccc}
\hline N.P. & $\begin{array}{c}\text { Concrete Model } \\
{[\mathrm{mm}]}\end{array}$ & $\begin{array}{c}\text { Reinforced Concrete Model } \\
{[\mathrm{mm}]}\end{array}$ & $\begin{array}{c}\text { Comparison } \\
\%\end{array}$ \\
\hline 1 & 0 & 0 & 0 \\
2 & 0.153 & 0.155 & 1.31 \\
3 & 0.306 & 0.309 & 0.98 \\
4 & 0.460 & 0.464 & 0.87 \\
5 & 0.613 & 0.618 & 0.82 \\
6 & 0.766 & 0.773 & 0.91 \\
7 & 0.919 & 0.927 & 0.87 \\
8 & 1.070 & 1.080 & 0.93 \\
9 & 1.230 & 1.240 & 0.81 \\
10 & 1.380 & 1.390 & 0.73 \\
\hline
\end{tabular}

Table 5. Maximum principal stress results

\begin{tabular}{cccc}
\hline N.P. & $\begin{array}{c}\text { Concrete Model } \\
{[\mathrm{MPa}]}\end{array}$ & $\begin{array}{c}\text { Reinforced Concrete Model } \\
{[\mathrm{MPa}]}\end{array}$ & $\begin{array}{c}\text { Comparison } \\
\%\end{array}$ \\
\hline 1 & -0.0785 & -0.0808 & 2.93 \\
2 & 0.1873 & 0.1906 & 1.76 \\
3 & 0.4531 & 0.4621 & 1.98 \\
4 & 0.7189 & 0.7334 & 2.02 \\
5 & 0.9847 & 1.0048 & 2.00 \\
6 & 1.2505 & 1.2762 & 2.06 \\
7 & 1.5163 & 1.5477 & 2.07 \\
8 & 1.7821 & 1.8181 & 2.02 \\
9 & 2.0479 & 2.0905 & 2.08 \\
10 & 2.3127 & 2.3619 & 2.13 \\
\hline
\end{tabular}

Table 6. Minimum principal stress results

\begin{tabular}{cccc}
\hline N.P. & $\begin{array}{c}\text { Concrete Model } \\
{[\mathrm{MPa}]}\end{array}$ & $\begin{array}{c}\text { Reinforced Concrete Model } \\
{[\mathrm{MPa}]}\end{array}$ & $\begin{array}{c}\text { Comparison } \\
\%\end{array}$ \\
\hline 1 & -0.6902 & -0.6983 & 1.17 \\
2 & -0.5676 & -0.5743 & 1.18 \\
3 & -0.4451 & -0.4503 & 1.17 \\
4 & -0.3225 & -0.3263 & 1.18 \\
5 & -0.1999 & -0.2023 & 1.20 \\
6 & -0.0774 & -0.0783 & 1.16 \\
7 & 0.0452 & 0.0457 & 1.11 \\
8 & 0.1667 & 0.1697 & 1.80 \\
9 & 0.2903 & 0.2936 & 1.14 \\
10 & 0.4128 & 0.4176 & 1.16 \\
\hline
\end{tabular}


Table 7. Maximum principal strain results

\begin{tabular}{cccc}
\hline N.P. & Concrete Model & Reinforced Concrete Model & $\begin{array}{c}\text { Comparison } \\
\%\end{array}$ \\
\hline 1 & 0.304 E-08 & 0.313 E-08 & 2.96 \\
2 & 0.803 E-06 & 0.822 E-06 & 2.37 \\
3 & 0.160 E-05 & 0.164 E-05 & 2.50 \\
4 & 0.240 E-05 & 0.244 E-05 & 1.67 \\
5 & 0.320 E-05 & 0.328 E-05 & 2.50 \\
6 & 0.400 E-05 & 0.410 E-05 & 2.50 \\
7 & 0.480 E-05 & 0.492 E-05 & 2.50 \\
8 & 0.560 E-05 & 0.573 E-05 & 1.17 \\
9 & 0.640 E-05 & 0.655 E-05 & 2.34 \\
10 & 0.720 E-05 & 0.737 E-05 & 2.36 \\
\hline
\end{tabular}

Table 8. Minimum principal strain results

\begin{tabular}{cccc}
\hline N.P. & Concrete Model & Reinforced Concrete Model & $\begin{array}{c}\text { Comparison } \\
\%\end{array}$ \\
\hline 1 & -0.278 E-05 & -0.286 E-05 & 2.88 \\
2 & -0.247 E-05 & -0.254 E-05 & 2.83 \\
3 & -0.215 E-05 & -0.221 E-05 & 2.79 \\
4 & -0.183 E-05 & -0.189 E-05 & 3.28 \\
5 & -0.151 E-05 & -0.156 E-05 & 3.31 \\
6 & -0.120 E-05 & -0.123 E-05 & 2.50 \\
7 & -0.879 E-06 & -0.908 E-06 & 3.30 \\
8 & -0.562 E-06 & -0.582 E-06 & 3.56 \\
9 & -0.245 E-06 & -0.256 E-06 & 4.49 \\
10 & 0.728 E-07 & 0.701 E-07 & 3.71 \\
\hline
\end{tabular}

When the non-linear analysis results of the bridge models were compared, the following results were obtained; the difference in maximum displacement is around $1 \%$, the difference in maximum principal stress is $2 \%$, the difference in minimum principal stress is $1 \%$, the difference in maximum principal strain is $2 \%$, and the difference in minimum principal strain is $4 \%$.

The results obtained from non-linear analyzes on non-reinforced concrete and reinforced concrete bridge models are given in Tables 9-13.

When the results of the analysis of the effective ground acceleration of reinforced and nonreinforced bridge models at $\mathrm{t}=1.900 \mathrm{sec}$ are compared; the results obtained were the same as the results of linear analysis. The reason for this situation can be stated as the displacement and strain values occur in very small amounts because the geometrical cross-section values of the bridge model used in the study are very small compared to a normal bridge. This means that the material constituting the model cannot reach the internal forces required to show the actual behavior. At this point, in order to investigate the effect of reinforcement on nonlinear behavior, bridge finite element models, which were previously modeled on $1 / 1$ scale, were doubled and the analyzes were repeated. The aim is to increase the dimensions of the model bridge to provide more displacement and deformation. 
Table 9. Maximum displacement results

\begin{tabular}{cccc}
\hline N.P. & $\begin{array}{c}\text { Concrete Model } \\
{[\mathrm{mm}]}\end{array}$ & $\begin{array}{c}\text { Reinforced Concrete Model } \\
{[\mathrm{mm}]}\end{array}$ & $\begin{array}{c}\text { Comparison } \\
\%\end{array}$ \\
\hline 1 & 0 & 0 & 0 \\
2 & 0.153 & 0.155 & 1.31 \\
3 & 0.306 & 0.309 & 0.98 \\
4 & 0.460 & 0.464 & 0.87 \\
5 & 0.613 & 0.618 & 0.82 \\
6 & 0.766 & 0.773 & 0.91 \\
7 & 0.919 & 0.927 & 0.87 \\
8 & 1.070 & 1.080 & 0.93 \\
9 & 1.230 & 1.240 & 0.81 \\
10 & 1.380 & 1.390 & 0.73 \\
\hline
\end{tabular}

Table 10. Maximum principal stress results

\begin{tabular}{cccc}
\hline N.P. & $\begin{array}{c}\text { Concrete Model } \\
{[\mathrm{MPa}]}\end{array}$ & $\begin{array}{c}\text { Reinforced Concrete Model } \\
{[\mathrm{MPa}]}\end{array}$ & $\begin{array}{c}\text { Comparison } \\
\%\end{array}$ \\
\hline 1 & -0.0785 & -0.0808 & 2.93 \\
2 & 0.1873 & 0.1906 & 1.76 \\
3 & 0.4531 & 0.4621 & 1.98 \\
4 & 0.7189 & 0.7334 & 2.02 \\
5 & 0.9847 & 1.0048 & 2.00 \\
6 & 1.2505 & 1.2762 & 2.06 \\
7 & 1.5163 & 1.5477 & 2.07 \\
8 & 1.7821 & 1.8181 & 2.02 \\
9 & 2.0479 & 2.0905 & 2.08 \\
10 & 2.3127 & 2.3619 & 2.13 \\
\hline
\end{tabular}

Table 11. Minimum principal stress results

\begin{tabular}{cccc}
\hline N.P. & $\begin{array}{c}\text { Concrete Model } \\
{[\mathrm{MPa}]}\end{array}$ & $\begin{array}{c}\text { Reinforced Concrete Model } \\
{[\mathrm{MPa}]}\end{array}$ & $\begin{array}{c}\text { Comparison } \\
\%\end{array}$ \\
\hline 1 & -0.6902 & -0.6983 & 1.17 \\
2 & -0.5676 & -0.5743 & 1.18 \\
3 & -0.4451 & -0.4503 & 1.17 \\
4 & -0.3225 & -0.3263 & 1.18 \\
5 & -0.1999 & -0.2023 & 1.20 \\
6 & -0.0774 & -0.0783 & 1.16 \\
7 & 0.0452 & 0.0457 & 1.11 \\
8 & 0.1667 & 0.1697 & 1.80 \\
9 & 0.2903 & 0.2936 & 1.14 \\
10 & 0.4128 & 0.4176 & 1.16 \\
\hline
\end{tabular}


Table 12. Maximum principal strain results

\begin{tabular}{cccc}
\hline N.P. & Concrete Model & Reinforced Concrete Model & $\begin{array}{c}\text { Comparison } \\
\%\end{array}$ \\
\hline 1 & 0.304 E-08 & 0.313 E-08 & 2.96 \\
2 & 0.803 E-06 & 0.822 E-06 & 2.37 \\
3 & 0.160 E-05 & 0.164 E-05 & 2.50 \\
4 & 0.240 E-05 & 0.244 E-05 & 1.67 \\
5 & 0.320 E-05 & 0.328 E-05 & 2.50 \\
6 & 0.400 E-05 & 0.410 E-05 & 2.50 \\
7 & 0.480 E-05 & 0.492 E-05 & 2.50 \\
8 & 0.560 E-05 & 0.573 E-05 & 1.17 \\
9 & 0.640 E-05 & 0.655 E-05 & 2.34 \\
10 & 0.720 E-05 & 0.737 E-05 & 2.36 \\
\hline
\end{tabular}

Table 13. Minimum principal strain results

\begin{tabular}{cccc}
\hline N.P. & Concrete Model & Reinforced Concrete Model & $\begin{array}{c}\text { Comparison } \\
\%\end{array}$ \\
\hline 1 & -0.278 E-05 & -0.286 E-05 & 2.88 \\
2 & -0.247 E-05 & -0.254 E-05 & 2.83 \\
3 & -0.215 E-05 & -0.221 E-05 & 2.79 \\
4 & -0.183 E-05 & -0.189 E-05 & 3.28 \\
5 & -0.151 E-05 & -0.156 E-05 & 3.31 \\
6 & -0.120 E-05 & -0.123 E-05 & 2.50 \\
7 & -0.879 E-06 & -0.908 E-06 & 3.30 \\
8 & -0.562 E-06 & -0.582 E-06 & 3.56 \\
9 & -0.245 E-06 & -0.256 E-06 & 4.49 \\
10 & 0.728 E-07 & 0.701 E-07 & 3.71 \\
\hline
\end{tabular}

Thus, the material used will transcend the elastic region and exhibit its real behavior. For the purpose stated above, the model bridge has been re-modeled in $2 / 1$ ratio by keeping the material properties and boundary conditions. Linear and nonlinear analyzes were repeated in the time domain by applying the Erzincan earthquake record on the models at 0.005 sec time intervals. The results obtained from the dynamic analyzes are shown below in comparison.

The results obtained for non-reinforced bridge model are given in Figs. 11-15. The blue lines on the graphs indicate the results of linear analysis, and the red lines represent the results of non-linear analysis.

When the graphs given above were examined, it was observed that the results of linear and nonlinear analysis were the same until $\mathrm{t}=1.830 \mathrm{sec}$, after this time step, the results of the nonlinear analysis remained constant while the results of linear analysis continued to increase. This was interpreted as the crack width in the tensile zone of the unreinforced concrete model exceeding the prescribed limit and reaching the carrying capacity. In other words, the earthquake force acting on the bridge model in this time step causes the concrete material to lose its strength.

The results obtained for reinforced bridge model are given in Figs. 16-20. The blue lines on the graphs indicate the results of linear analysis, and the red lines represent the results of non-linear analysis. 


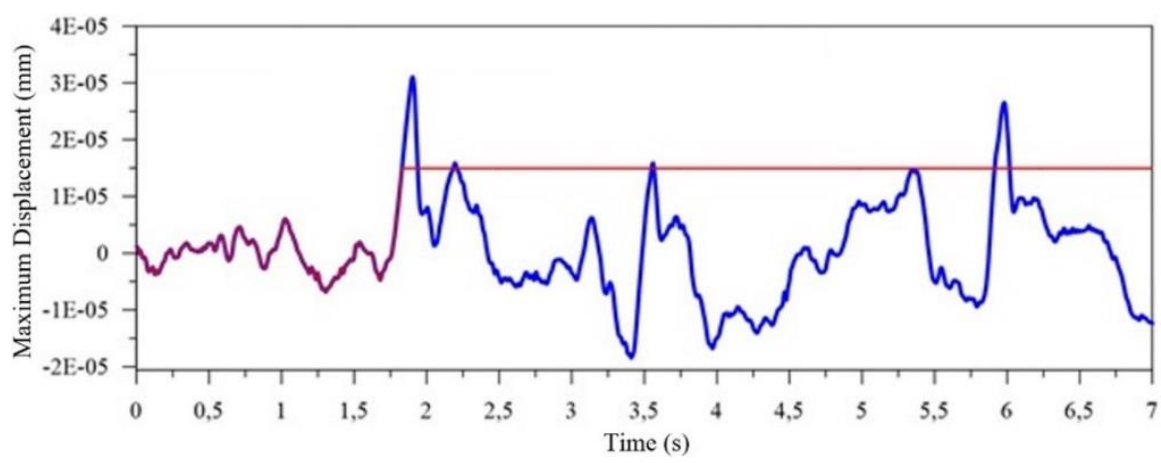

Fig. 11. Maximum displacement results

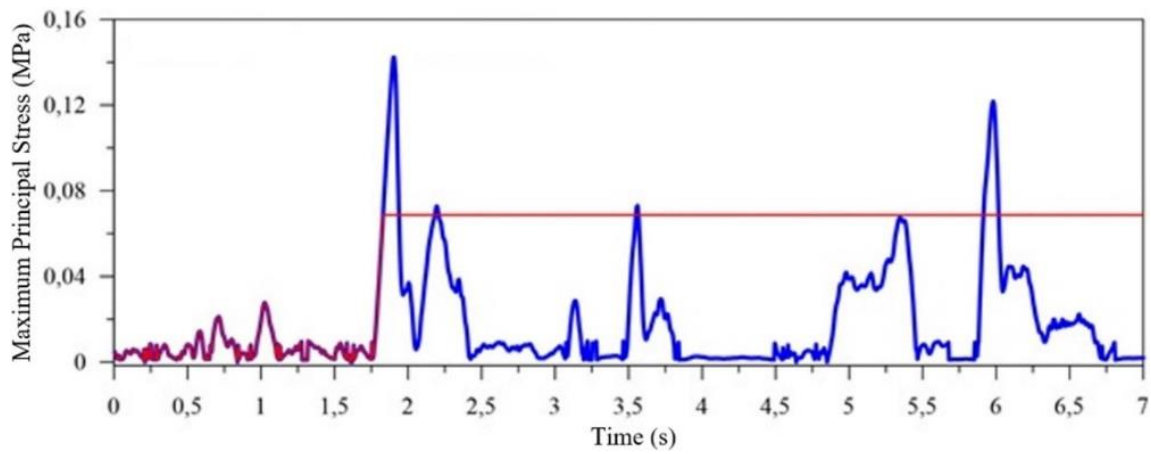

Fig. 12. Maximum principal stress results

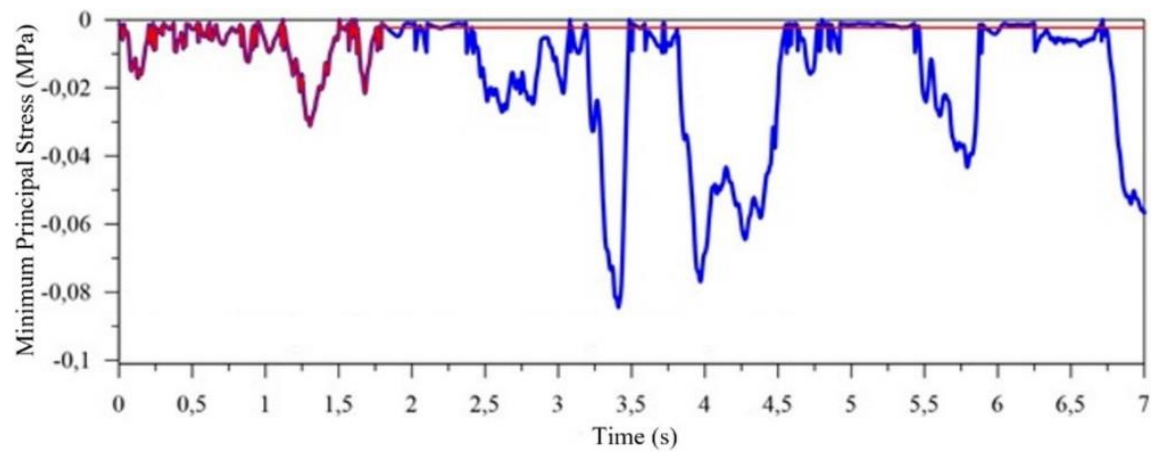

Fig. 13. Minimum principal stress results

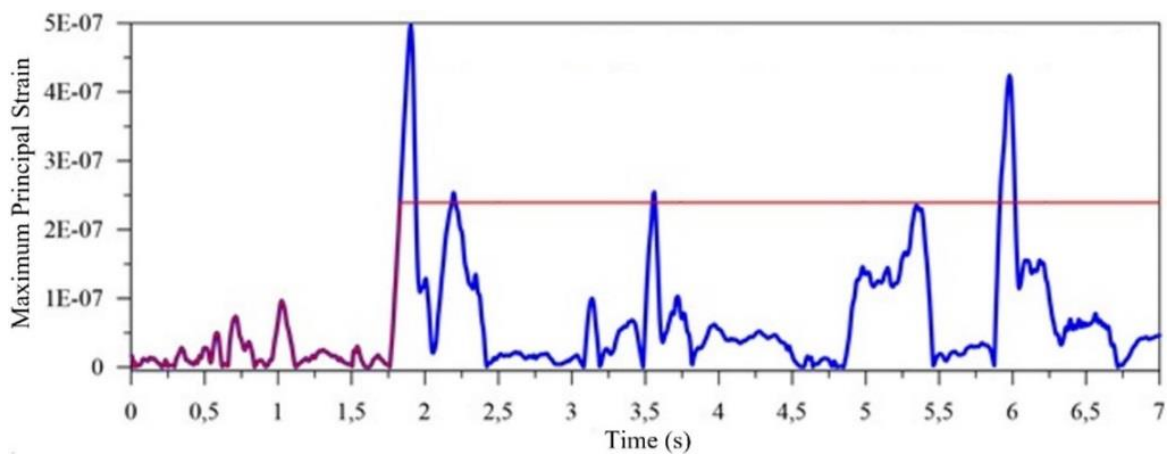

Fig. 14. Maximum principal strain results 


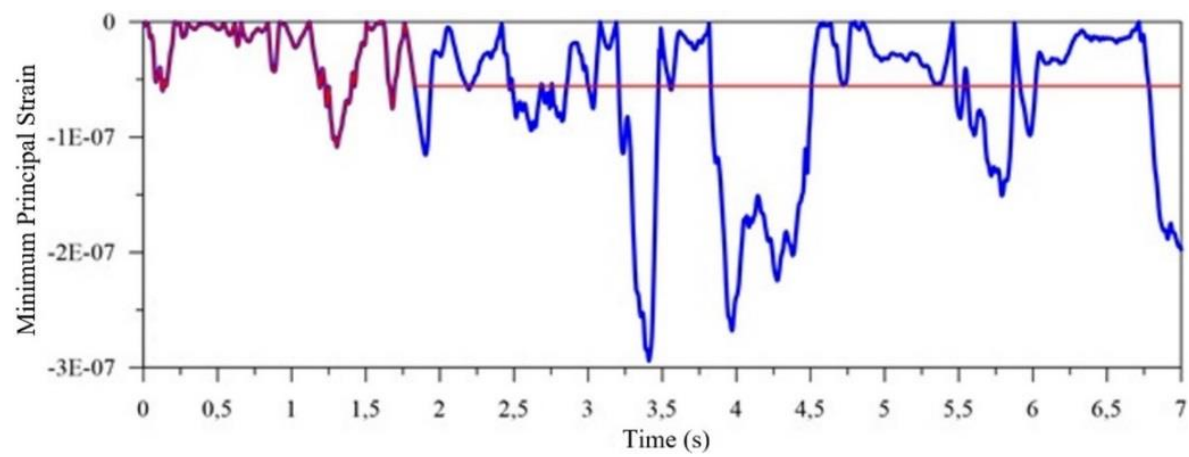

Fig. 15. Minimum principal strain results

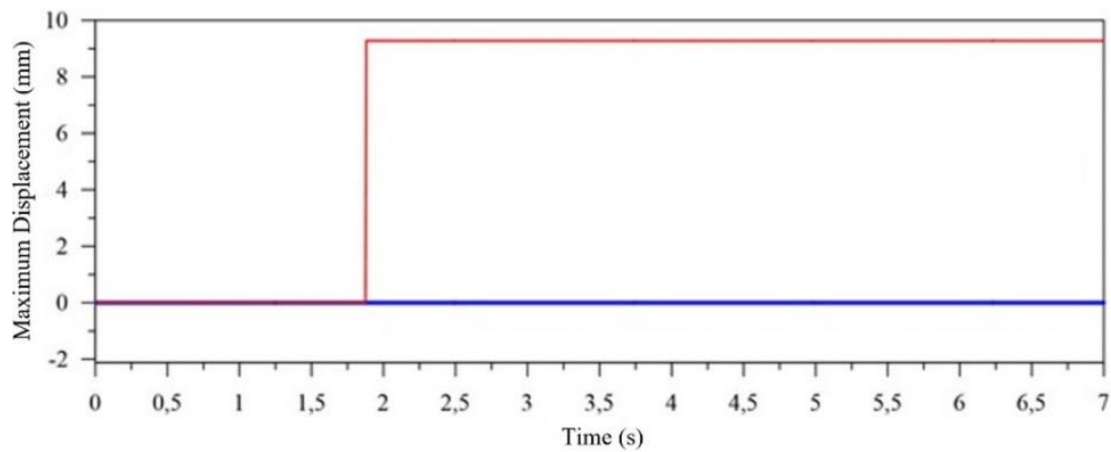

Fig. 16. Maximum displacement results

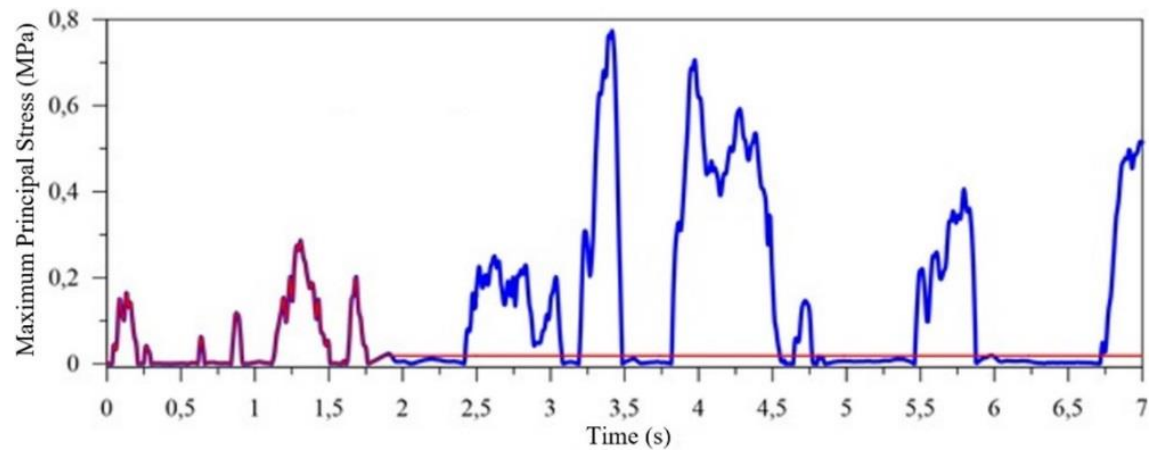

Fig. 17. Maximum principal stress results

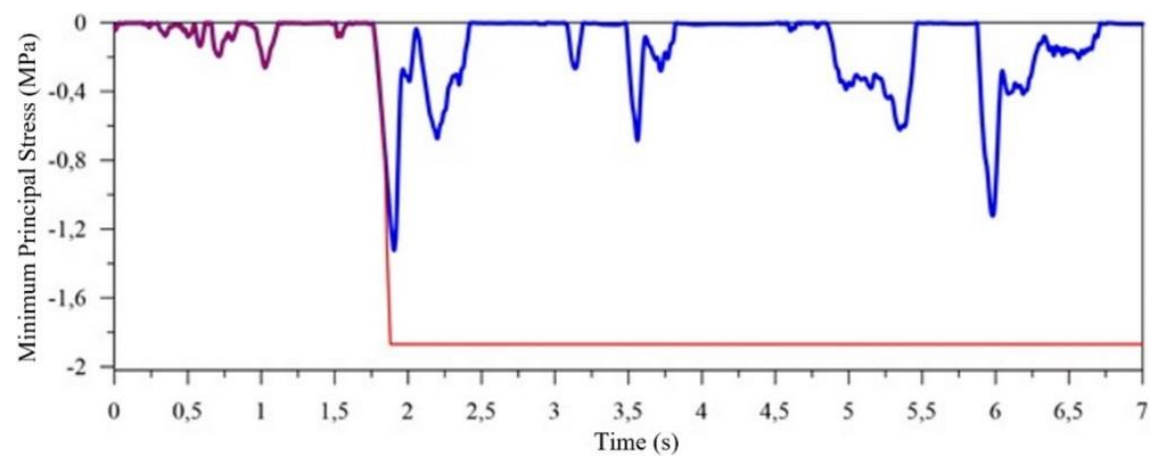

Fig. 18. Minimum principal stress results 


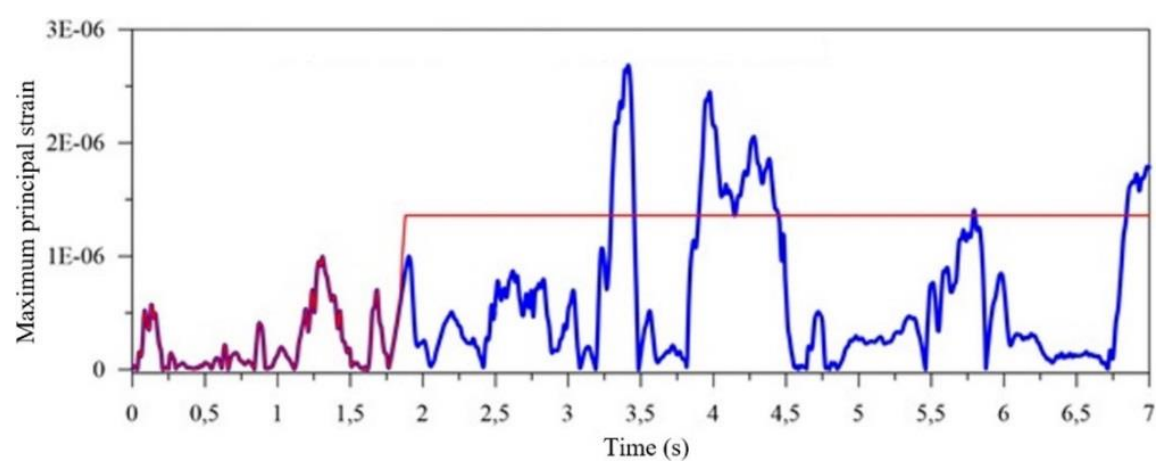

Fig. 19. Maximum principal strain results

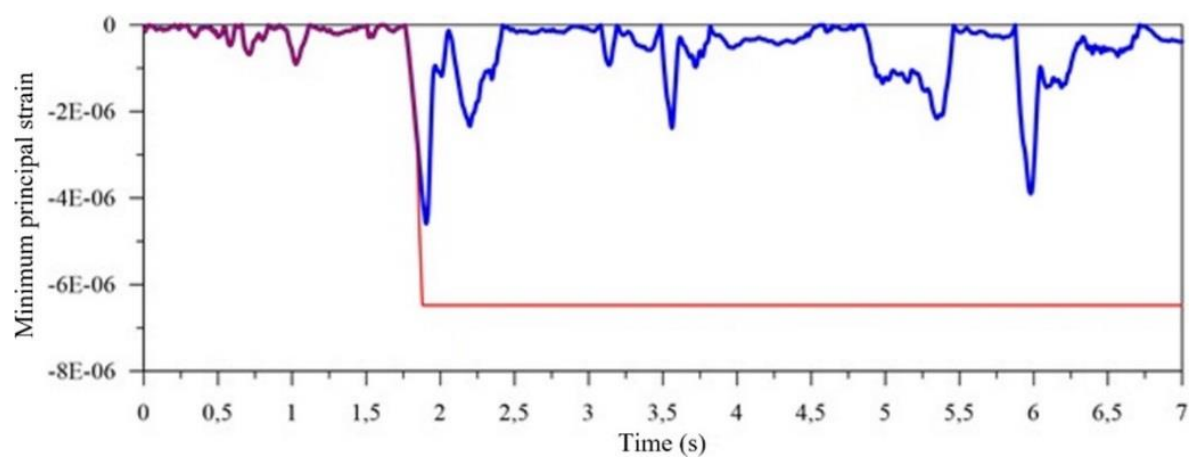

Fig. 20. Minimum principal strain results

When the graphs given above are examined, it is seen that there are changes in the results at $\mathrm{t}=$ 1.830 and $\mathrm{t}=1.880$ time steps. The linear and nonlinear analysis results of the reinforced concrete model are the same until $t=1.830 \mathrm{sec}$. After this time step, the results of the linear analysis continue to change, while the results of the non-linear analysis increase at a constant slope. This increase continued until $\mathrm{t}=1.880$ seconds and the graph remained constant after this time step. Linear analysis results continued to change.

Considering the results of the unreinforced concrete model, it was previously determined that the section represented by the concrete material in the tensile zone of the model had already lost its strength and plasticized in $\mathrm{t}=1.830$ seconds. Considering a reinforced concrete structure, the next step under the influence of bending moment is the yielding of reinforcement. Accordingly, the event occurring at $\mathrm{t}=1.880$ seconds was evaluated as the yielding of reinforcement in the tensile zone. Therefore, the linear and nonlinear results were the same up to $t=1.830$ seconds. In the nonlinear analysis results, the concrete lost its strength at this point, but it allowed the reinforcement structure to carry some more stress.

\section{Conclusions}

In this study, it is aimed to be searched the effect of the reinforcement to the structural behavior of reinforced concrete bridges formed with the finite element method. For this purpose, the numerical model of the bridge with known dimensions, material properties and reinforcement layout was modeled using ANSYS finite element analysis program. In the first model, it was thought that the bridge was constructed using only concrete, reinforcement was not taken into consideration. Then the same bridge was modelled without changing the boundary conditions as if it was built by reinforced concrete material in which reinforcement and concrete were together and the modal analyses were carried out on this model again. The dynamic characteristics of the two 
different bridge models were determined using numerical methods and the effect of the reinforcement on these characteristics was presented by comparing them with each other. In addition, linear and nonlinear dynamic analyzes were performed on the reinforced and unreinforced finite element models of the bridge model using the effective earthquake acceleration record of the Erzincan earthquake of 1992 and structural behavior was evaluated.

The conclusions obtained from the studies are given in detail below.

\subsection{Conclusions of modal analyses}

$\checkmark$ The first eight natural frequencies were obtained between $45.305-216.83 \mathrm{~Hz}$ for unreinforced concrete and 45.967- $218.61 \mathrm{~Hz}$ for the reinforced concrete model.

$\checkmark$ Natural frequencies of unreinforced and reinforced models are very close to each other.

$\checkmark$ The mode shapes obtained from finite element analysis of the unreinforced and reinforced models of the bridge examined are in agreement with each other. Mode shapes are obtained as elongation, vertical and transverse modes. This shows that modal analyzes performed on finite element models are applied correctly.

$\checkmark$ When the natural frequencies obtained from the finite element analysis of the unreinforced and reinforced models of the investigated bridge were examined, it was found that there was a maximum difference of $2 \%$ between the frequencies.

\subsection{Conclusions of linear time history analyses}

$\checkmark$ It was observed that the displacements increased towards the middle of the bridge span. The maximum vertical displacement value was $1.38 \mathrm{~mm}$ for the unreinforced model and 1.39 $\mathrm{mm}$ for the reinforced model. The difference between displacement values around is $1 \%$.

$\checkmark$ It was observed that the maximum principal stress value increased towards the top of the points where the bridge deck joins the piers. The maximum principal stress value was $2.314 \mathrm{MP}$ for the non-reinforced model and 2.32 MPa for the reinforced model. The difference between maximum principal stress values is around $2 \%$.

$\checkmark$ It was observed that the minimum principal stress value increased towards the bridge piers and deck end regions. The minimum prime stress value was obtained as $-0.6902 \mathrm{MPa}$ for the unreinforced model and $-0.6983 \mathrm{MPa}$ for the reinforced model. The difference between minimum principal stress values is around $1 \%$.

$\checkmark$ It was observed that the maximum strain value increased towards the middle of the bridge span. The maximum strain value was $0.720 \mathrm{E}-5$ for the unreinforced model and $0.737 \mathrm{E}-5$ for the reinforced model. The difference between maximum strain values is around $2 \%$.

$\checkmark$ It was observed that the minimum strain value increased towards the bridge piers and deck end regions. The minimum strain value is obtained as -0.278 E- 5 for the unreinforced model and $0.286 \mathrm{E}-5$ for the reinforced model. The difference between minimum strain values is around $2 \%$.

\subsection{Conclusions of non-linear time history analyses}

In the evaluations based on deformations such as nonlinear analyzes, it was evaluated that many parameters including inaccurate approaches and assumptions were used together and therefore the results of the calculations were valid in accordance with the assumptions. Accordingly, it was evaluated that it is not a valid approach to obtain the exact sensitivity of the reinforcement on nonlinear behavior alone. Therefore it is concluded that reinforcement affects the analysis results and therefore it is more accurate to model finite element models of reinforced concrete structures in non-linear analysis, but not only concrete material but also reinforcement with concrete.

In summary, when the results obtained from this study are evaluated, it can be said that the reinforcement has no effect on the modal and linear dynamic behavior of reinforced concrete bridges. This will provide significant facilities for carrying out such analyzes. However, the reinforcement has 
an effect on the nonlinear dynamic behavior of reinforced concrete bridges, so it would be more accurate to consider the reinforcement in the construction of the numerical model in the structures where such analyzes will be performed.

\section{Declaration of conflicting interests}

The author(s) declared no potential conflicts of interest with respect to the research, authorship, and/or publication of this article.

\section{References}

[1] Pang J. Modeling and experimental modal analysis of highway bridge. PhD Thesis. University of Oklahama, 1996.

[2] Kou JW, DeWolf JT (1997) Vibrational behavior of continuous span highway bridge-influencing variables. Journal of Structural Engineering 123: 333-344.

[3] Fryba L, Pirner M (2001) Load tests and modal analysis of bridges. Engineering Structures 23: 102-109.

[4] Halling MW, Muhammad I, Womack KC (2001) Dynamic field testing for condition assessment bridge bents. Journal of Structural Engineering ASCE 127: 161-167.

[5] Wang TL, Zong Z. Improvement of evaluation method for existing highway bridges. Report No: FL/DOT/RMC/6672-818. Structural Research Center, Florida Department of Transportation, Miami, Florida, USA, 2002.

[6] Xu F. Health assessment and monitoring of a posttensioned segmental concrete bridge. PhD Thesis. University of Illinois, 2002.
[7] Zapico JL, Gonzalez MP, Friswell MI, Taylor CA, Crewe AJ (2003) Finite element model updating of a small scale bridge. Journal of Sound and Vibration 268: 993-1012.

[8] Owen JS, Haritos N (2003) Damage detection in large-scale laboratory bridge models. Key Engineering Materials 245-246: 35-42.

[9] Ren WX, Zatar W, Harik IE (2004) Ambient vibration-based seismic evaluation of a continuous girder bridge. Engineering Structures 26: 631-640.

[10] El-Borgi S, Smaoui H, Cherif F, Bahlous S, Gharairi A (2004) Modal identification and finite element model updating of a reinforced concrete bridge. Emirates Journal for Engineering Research 9: 29-34.

[11] Sgambi L (2004) Fuzzy theory based approach for three-dimensional nonlinear analysis of reinforced concrete two-blade bridge piers. Computer and Structures 82: 1067-1076.

[12] Bagchi A (2005) Updating the mathematical model of a structure using vibration data. Journal of Vibration and Control 11-12: 1469-1486.

[13] Wu Q, Yoshimura M, Takahashi K, Nakamura S, Nakamura T (2006) Nonlinear seismic properties of the second saikai bridge a concrete filled tubular (CFT) arch bridge. Engineering Structures 28: 163182.

[14] Whelan MJ, Gangone MV, Janoyan KD, Jha R (2009) Real-time wireless vibration monitoring for operational modal analysis of an integral abutment highway bridge. Engineering Structures 31: 22242235.

[15] Altunışı AC. Determination of structural behavior of highway bridges by numerical and experimental methods. PhD Thesis. Karadeniz Technical University, 2010 (in Turkish).

[16] ANSYS (2015) Swanson Analysis Systems, Pennsylvania, USA. 